\title{
ORIGINAL
}

ARTICLES

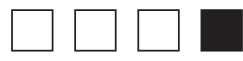

\section{Racial Justice Curricula in Family Medicine Residency Programs: A CERA Survey of Program Directors}

Maria Harsha Wusu, MD, MSEd; Marielle Baldwin, MD, MPH; Afi M. Semenya, MD, MPH; Gerardo Moreno, MD, MSHS; Stephen A. Wilson, MD, MPH

BACKGROUND AND OBJECTIVES: Structural racism is a cause of health disparities. Graduate medical education is tasked with training physicians who understand and address disparities. Addressing health disparities includes education on racism, such as racial justice curricula (RJC). We surveyed program directors (PDs) about the prevalence and characteristics of RJC in family medicine residency programs (FMRPs).

METHODS: RJC questions were included in the 2020 Council of Academic Family Medicine Educational Research (CERA) survey of FMRP PDs. We calculated univariate and bivariate statistics to describe respondent characteristics and attitudes, program characteristics, curriculum characteristics, and barriers to implementation.

RESULTS: Of 624 PDs, 312 (50\%) responded and 283/312 (90.7\%) completed RJC questions. Less than one-third of FMRPs reported RJC, of which $98.9 \%$ focused on implicit/unconscious bias. Program characteristics associated with RJC included location, percent underrepresented minorities in medicine (URMM) residents and faculty, and percent patients identifying as Black, Latino/a, and Native American. FMRPs with RJC were more likely to have PDs who reported favorable attitudes toward including RJC and believed it is important for family physicians to understand structural racism. The greatest barrier to implementation of RJC was lack of faculty training.

CONCLUSIONS: In this national survey, most FMRPs reported no RJC. Most respondent PDs endorsed that it is important for family physicians to understand structural racism and that RJC should be included in residency. Lack of faculty training was the greatest barrier to implementation. Research is needed to evaluate existing RJC and explore strategies for overcoming barriers to implemention.

(Fam Med. 2022;54(2):114-22.)

doi: 10.22454/FamMed.2022.189296

$\mathbf{T}$ he Accreditation Council for Graduate Medical Education (ACGME) has tasked residency programs with educating physicians who understand health disparities and are trained to reduce them. ${ }^{1}$ Health disparities are the differences in health and health

care between groups that are closely linked with social, economic, and/ or environmental disadvantage. ${ }^{2}$ Structural racism is a root cause of health disparities. ${ }^{3}$ Structural racism is defined as "a system in which public policies, institutional practices, cultural representations, and other norms work in various, often reinforcing ways to perpetuate racial group inequity.",5 This system routinely advantages White people "while producing cumulative and chronic adverse outcomes for people of color."' Despite the demonstrated relationship between structural racism and health disparities, few formal curricula focused on racism exist. ${ }^{7,8}$ Additionally, there is no published data on the prevalence of education focused on racism in residency programs or the barriers to implementing curricula in this content area.

Medical education aimed at addressing health disparities has traditionally been presented as content without context. ${ }^{9,10}$ For example, medical students and residents often learn that Black Americans have the highest rates of hypertension without concurrently learning about how structural racism has resulted in Black people having higher rates of uninsurance than White people and Black communities having a higher proportion of fast food restaurants and less access to healthy foods and green space than White communities. ${ }^{11-13}$ In addition,
From the Department of Family Medicine, Morehouse School of Medicine, Atlanta, GA (Dr Wusu); Department of Family Medicine, Boston University Medical Center, Boston, MA (Drs Baldwin, Semenya, and Wilson); Department of Family Medicine, University of California Los Angeles (Dr Moreno). 
traditional disparities lectures fail to address the significance of racial discrimination and bias, despite data demonstrating a relationship between greater lifetime discrimination and increased risk of hypertension, and research showing that most clinicians have implicit bias that reflects negative attitudes toward people of color. ${ }^{14,15}$ Identifying racial differences without addressing racism has the potential to reinforce negative stereotypes and the falsity of inherent biological difference between races, rather than promote necessary self-reflection..$^{5,9}$

Education focused on structural racism is especially relevant to the field of family medicine as family physicians are trained to care for people of all ages in the context of their communities. Our professional organizations condemn racism, acknowledge its impact on health and the health care system, and encourage institutions and residency programs to adopt antiracist action, including curriculum. ${ }^{16-20}$ Family physicians provide the majority of care to the nation's underresourced communities, which are largely Black, Latino, and Indigenous communities. ${ }^{21-23}$ Providing formal, structured curriculum on racism, in the form of racial justice curriculum (RJC), can equip family medicine residents and faculty to think critically about how to use their roles as clinicians, educators, and researchers to address health disparities. ${ }^{9,10}$

This study aimed to determine the prevalence of formal RJC in family medicine residency programs (FM$\mathrm{RPs}$ ), assess program director beliefs about the importance of such curriculum, identify perceived barriers to implementation of formal $\mathrm{RJC}$, and determine specific program characteristics that may correlate with the presence of formal RJC. We defined formal RJC as one or more educational sessions for residents, accompanied by goals and objectives that specifically address structural racism. We hypothesized that (1) the majority of program directors would agree that formal RJC should be included in FMRPs, but that most programs would not have such a curriculum; (2) other than time, lack of faculty training would be the most important barrier to implementing formal RJC; and (3) FMRPs with more residents who identify as Black, Latino/a, and/or Native American, the groups designated as underrepresented minorities in medicine (URMM), or where the majority of patients identify as Black, Latino/a and/or Native American would be more likely to have formal RJC.

\section{Methods}

Study Design and Data

Collection

The questions were part of a larger omnibus survey conducted by the Council of Academic Family Medicine Educational Research Alliance (CERA). The methodology of the CERA Program Director Survey has previously been described. ${ }^{24}$ The CERA Steering Committee evaluated questions for consistency with the overall subproject aim, readability, and existing evidence of reliability and validity. The questions were pretested on family medicine educators who were not part of the target population. The American Academy of Family Physicians Institutional Review Board approved the study in September 2020. Data were collected from September 23, 2020 to October 16, 2020.

The sampling frame for the survey was all ACGME-accredited US family medicine residency program directors as identified by the Association of Family Medicine Residency Directors (AFMRD). Email invitations to participate were delivered with the survey using the online program SurveyMonkey. Two follow-up emails to encourage nonrespondents to participate were sent weekly after the initial email invitation, and a third reminder was sent 2 days before the survey closed. There were 693 program directors at the time of the survey, one of whom had no email address listed (692 total); 28 had previously opted out of surveys or their emails were undeliverable. Therefore, the survey was emailed to 664 individuals and contained a qualifying question to remove programs that had not had three resident classes. Forty program directors indicated that they did not meet criteria, so these responses were omitted, reducing the sample size to 624 and respondents to 312 .

\section{Measures}

The primary variable of interest was the presence of RJC (one item, yes/ no) in family medicine residency training programs. For the purpose of this survey, racial justice is defined as "the creation and proactive reinforcement of policies, practices, attitudes, and actions that produce equitable power, access, opportunities, treatment and outcomes for all people, regardless of race. Examples of formal RJC include education on (1) the history of racism in medicine; (2) the levels of racism (personallymediated, internalized, institutional, and structural) and how they appear in our interactions with patients, staff, and colleagues; and (3) training on implicit or unconscious racial bias that acknowledges structural racism. It is separate from or in addition to curriculum focused solely on the social determinants of health, health disparities, community medicine, advocacy, or cultural competency.

The racial justice-specific module consisted of 11 questions. All questions allowed for one response per question, except for the last question, which asked respondents to identify the two most important barriers to the implementation of RJC. The module also asked about residency program characteristics: percent Black, Latino/a, and Native American patients served by residents (one item), RJC curriculum components (two items), program director attitudes (two items), and barriers to implementation of a curriculum (four items).

Program directors were asked identifying questions about themselves (medical training, gender, race/ ethnicity, years as program director [PD]) and about their residency program (structure, location, number of residents, size of community, percent 
URMM residents, percent URMM faculty, and proportion of international medical graduates [IMGs]). Percent URRM faculty was dichotomized (yes/no) to indicate "no" versus "any URMM faculty."

\section{Analysis}

We analyzed data using Stata version 15 (College Station, TX). We calculated univariate statistics for all variables, and we computed bivariate statistics to examine the association between the presence of RJC and (1) program and PD characteristics, (2) PD attitudes about RJC, (3) RJC components, and (4) barriers to implementation of RJC. We used $\chi^{2}$ tests and student $t$ tests to evaluate bivariate relationships, using a $P$ value of $<.05$ to define statistical significance.

\section{Results}

\section{Residency Characteristics}

The overall response rate for the CERA survey was 50\% (312/624); $91 \%$ of respondents completed the racial justice module (283/312). Table 1 describes the characteristics of all residency program respondents. The majority of FMRPs were community-based, university-affiliated residences $(59.3 \%, 168 / 283)$. Most FMRPs were located in the Midwest $(26.8 \%, 76 / 283)$ and the West $(22.2$ $\%, 63 / 283)$.
Characteristics of Residency

Programs with RJC

Of the 283 PDs who completed the RJC module, 87 reported that their FMRP had racial justice curriculum (30.7\%). Most residences with RJC (46\%) were moderately sized (19-31 residents) and more likely to have 0\%-24\% international medical graduates compared to programs without RJC (78\% vs 56\%, respectively, $P<.05)$. FMRPs with more residents who identified as URMM were more likely to have RJC, a statistically significant association. FMRPs with RJC were more likely to have one or more URMM faculty compared to programs without RJC (72.4\% vs $27.6 \%, P<.05)$. FMRPs with RJC

Table 1: Characteristics of Family Medicine Residency Programs

\begin{tabular}{|c|c|c|c|}
\hline Residency Program Characteristics & $\begin{array}{c}\text { All Residency Programs } \\
\text { ( } \mathrm{N}=\mathbf{2 8 3}) \\
\mathrm{n}(\%)\end{array}$ & $\begin{array}{c}\text { Racial Justice } \\
\text { Curriculum ( } \mathrm{N}=87) \\
n(\%)\end{array}$ & $\begin{array}{c}\text { No Racial Justice } \\
\text { Curriculum (N=196) } \\
n(\%)\end{array}$ \\
\hline \multicolumn{4}{|l|}{ Residency Structure } \\
\hline University based & $44(15.6)$ & $18(20.7)$ & $26(13.3)$ \\
\hline Community based, university affiliated & $168(59.4)$ & $50(57.5)$ & $118(60.2)$ \\
\hline Community based, nonaffiliated & $63(22.3)$ & $17(19.5)$ & $46(23.5)$ \\
\hline Military/other & $8(2.8)$ & $2(2.3)$ & $6(3.1)$ \\
\hline \multicolumn{4}{|l|}{ Residency location/region*,† } \\
\hline Northeast & $58(20.5)$ & $20(23.0)$ & $38(19.3)$ \\
\hline South Atlantic & $45(15.9)$ & $19(21.8)$ & $26(13.3)$ \\
\hline South & $42(14.8)$ & $6(6.9)$ & $36(18.4)$ \\
\hline Midwest & $76(26.8)$ & $20(23.0)$ & $56(28.6)$ \\
\hline West & $62(21.9)$ & $22(25.3)$ & $40(20.4)$ \\
\hline \multicolumn{4}{|l|}{ Size of Community } \\
\hline Less than 30,000 & $30(10.6)$ & $6(6.9)$ & $24(12.3)$ \\
\hline 30,000 to 74,000 & $529(18.4)$ & $15(17.2)$ & $37(19.0)$ \\
\hline 75,000 to 149,999 & $55(19.5)$ & $15(17.2)$ & $40(20.5)$ \\
\hline 150,000 to 499,000 & $68(24.1)$ & $23(26.4)$ & $45(23.1)$ \\
\hline 500,000 to 1 million & $35(12.4)$ & $8(9.2)$ & $27(13.9)$ \\
\hline More than 1 million & $42(14.9)$ & $20(23.0)$ & $22(11.3)$ \\
\hline \multicolumn{4}{|l|}{ International Medical Graduates* } \\
\hline $0 \%-24 \%$ & $176(62.9)$ & $67(77.9)$ & $109(56.2)$ \\
\hline $25 \%-49 \%$ & $43(15.4)$ & $11(12.8)$ & $32(16.5)$ \\
\hline $50 \%-74 \%$ & $36(12.9)$ & $5(5.8)$ & $31(16.0)$ \\
\hline $75 \%-100 \%$ & $25(8.9)$ & $3(3.5)$ & $22(11.3)$ \\
\hline
\end{tabular}


Table 1: Continued

\begin{tabular}{|c|c|c|c|}
\hline Residency Program Characteristics & $\begin{array}{l}\text { All Residency Programs } \\
(\mathrm{N}=\mathbf{2 8 3}) \\
\mathrm{n}(\%)\end{array}$ & $\begin{array}{c}\text { Racial Justice } \\
\text { Curriculum ( }=87) \\
n(\%)\end{array}$ & $\begin{array}{c}\text { No Racial Justice } \\
\text { Curriculum }(\mathrm{N}=196) \\
n(\%)\end{array}$ \\
\hline \multicolumn{4}{|l|}{ Number of Residents in Residency } \\
\hline$<19$ & $108(38.3)$ & $30(34.5)$ & $78(40.0)$ \\
\hline $19-31$ & $131(46.5)$ & $40(46.0)$ & $91(46.7)$ \\
\hline$>31$ & $43(15.2)$ & $17(19.5)$ & 26 (13.3) \\
\hline \multicolumn{4}{|l|}{ Percent URMM Residents* } \\
\hline $0 \%$ & $31(11.0)$ & $6(6.9)$ & $25(12.8)$ \\
\hline $1 \%-5 \%$ & $35(12.4)$ & $6(6.9)$ & $29(14.9)$ \\
\hline $6 \%-10 \%$ & $61(21.6)$ & $19(21.8)$ & $42(21.5)$ \\
\hline $11 \%-20 \%$ & $60(21.8)$ & $16(18.4)$ & $44(22.6)$ \\
\hline $21 \%-30 \%$ & $44(15.6)$ & $15(17.2)$ & $29(14.9)$ \\
\hline $31 \%-50 \%$ & $33(11.7)$ & $17(19.5)$ & $16(8.2)$ \\
\hline$>50 \%$ & $18(6.4)$ & $8(9.2)$ & $10(5.1)$ \\
\hline \multicolumn{4}{|l|}{ Percent URMM Faculty $\neq$} \\
\hline $0 \%$ & $105(37.1)$ & $24(27.6)$ & $81(41.3)$ \\
\hline $1 \%-5 \%$ & $37(13.1)$ & $16(18.4)$ & $21(10.7)$ \\
\hline $6 \%-10 \%$ & $37(13.1)$ & $12(13.8)$ & $25(12.8)$ \\
\hline $11 \%-20 \%$ & $48(17.0)$ & $18(20.7)$ & $30(15.3)$ \\
\hline $21 \%-30 \%$ & $24(8.5)$ & $7(8.1)$ & $17(8.7)$ \\
\hline $31 \%-50 \%$ & $23(8.1)$ & $9(10.3)$ & $14(7.1)$ \\
\hline$>50 \%$ & $9(3.2)$ & $1(1.2)$ & $8(4.10$ \\
\hline Any URMM faculty* & $178(62.9 \%)$ & $63(72.4)$ & $115(58.7)$ \\
\hline \multicolumn{4}{|l|}{$\begin{array}{l}\text { Percent Patients Black, Latino, and/or } \\
\text { Native American Served by Residents * }\end{array}$} \\
\hline $0 \%$ & $2(0.7)$ & $0(0.0)$ & $2(1.0)$ \\
\hline $1 \%-10 \%$ & 39 (13.9) & $4(4.6)$ & $35(18.0)$ \\
\hline $11 \%-25 \%$ & $66(23.5)$ & $20(23.0)$ & $46(23.7)$ \\
\hline $26 \%-50 \%$ & $93(33.10$ & $33(37.9)$ & $60(30.9)$ \\
\hline$>50 \%$ & $81(28.8)$ & $30(34.5)$ & $51(26.3)$ \\
\hline
\end{tabular}

Abbreviation: URMM, underrepresented minority in medicine.

${ }^{*} P<.05$, comparison is between programs with and without a racial justice curriculum.

${ }^{\dagger}$ Northeast = New England (NH, MA, ME, VT, RI, or CT) and Middle Atlantic (NY, PA, or NJ); West = Pacific (WA, OR, CA, AK, or HI) and Mountain (MT, ID, WY, NV, UT, AZ, CO, or NM); Midwest = East North Central (WI, MI, OH, IN, or IL) and West North Central (ND, MN, SD, IA, NE, KS, or MO); South = West South Central (OK, AR, LA, or TX) and East South Central (KY, TN, MS, or AL); and South Atlantic = FL, GA, SC, NC, VA, DC, WV, DE, PR, or MD.

$\mathrm{URMM}=$ Black, Latino (Mexican-American, mainland Puerto Ricans), and/or Native American (American Indian, Alaska Native, and Native Hawaiian).

were more likely to serve patient populations where the majority identified as Black, Latino/a, and/or Native American $(P<.05$, Table 1$)$.

Program Director Characteristics The majority of $\mathrm{PD}$ respondents in FMRPs both with and without formal RJC identified as White (87.4\% and $83.2 \%$ respectively, Table 2). Of the FMRPs with formal RJC, a majority had female PDs (51.2\%) compared to $40.9 \%$ female PDs in FMRPs without formal RJC (Table 2).

\section{Program Director Attitudes}

Of the 283 PDs, the majority (88.7\%) believed that it is important for family physicians to understand structural racism. Most PDs (67.1\%) believed that formal RJC should be included in a FMRP; $32.9 \%$ of PDs were either neutral or did not believe 
that formal RJC should be included in a FMRP; $11.7 \%$ of PDs did not believe that structural racism is important for family physicians to understand (Table 3).
Among the 87 FMRPs that do have formal RJC, the majority of PD respondents $(78 / 87,89.7 \%)$ believed that formal RJC should be included in training program curricula, and $95.4 \%$ (83/87) believed that it is important for family physicians to understand structural racism. The majority of FMRPs without RJC also positively endorsed the importance of RJC for residency training $(57.1 \%)$ and family physicians

Table 2: Characteristics of Family Medicine Residency Programs Directors Stratified by Programs With or Without a Racial Justice Curriculum

\begin{tabular}{|c|c|c|c|}
\hline Residency Program Director Characteristics & $\begin{array}{c}\text { All Residency } \\
\text { Programs }(\mathrm{N}=283) \\
n(\%)\end{array}$ & $\begin{array}{c}\text { Racial Justice } \\
\text { Curriculum }(\mathrm{N}=87) \\
n(\%)\end{array}$ & $\begin{array}{c}\text { No Racial Justice } \\
\text { Curriculum (N=196 } \\
n(\%)\end{array}$ \\
\hline \multicolumn{4}{|l|}{ Training Category } \\
\hline MD & $231(81.9)$ & $74(85.1)$ & $157(80.5)$ \\
\hline $\mathrm{DO}$ & $51(18.1)$ & $13(14.9)$ & $38(19.5)$ \\
\hline Years as a program director, mean (SD) & $7.0(6.4)$ & $7.4(6.7)$ & $6.8(6.3)$ \\
\hline Years in current program director role, mean (SD) & $6.1(5.8)$ & $6.2(5.7)$ & $6.0(5.9)$ \\
\hline Female program director & $122(43.6)$ & $43(51.2)$ & $79(40.9)$ \\
\hline Latino/a ethnicity & $21(7.5)$ & $4(4.6)$ & $17(8.8)$ \\
\hline \multicolumn{4}{|l|}{ Race } \\
\hline White & $239(84.5)$ & $76(87.4)$ & $163(83.2)$ \\
\hline Asian & $20(7.1)$ & $5(5.6)$ & $15(7.7)$ \\
\hline Black & $12(4.2)$ & $3(3.5)$ & $9(4.6)$ \\
\hline Other* & $12(4.2)$ & $3(3.5)$ & $9(4.6)$ \\
\hline
\end{tabular}

* Other=Hawaiian or Pacific Islander/Native American/declined.

Table 3: Program Director Attitudes Towards Inclusion of Racial Justice Curriculum in Family Medicine Training and the Importance for Family Physicians to Understanding Structural Racism

\begin{tabular}{|c|c|c|c|c|c|c|}
\hline \multirow[b]{2}{*}{ Survey Question } & \multicolumn{3}{|c|}{$\begin{array}{l}\text { Formal RJC Should Be Included in } \\
\text { Family Medicine Residency Training }\end{array}$} & \multicolumn{3}{|c|}{$\begin{array}{l}\text { Important for Family Physicians to } \\
\text { Understand Structural Racism }\end{array}$} \\
\hline & $\begin{array}{l}\text { Agree or } \\
\text { Strongly Agree } \\
(\mathrm{N}=190)\end{array}$ & $\begin{array}{l}\text { Neutral or } \\
\text { Disagree } \\
\text { or Strongly } \\
\text { Disagree } \\
(\mathrm{N}=93)\end{array}$ & $P$ Value & $\begin{array}{l}\text { Agree or } \\
\text { Strongly Agree } \\
(\mathrm{N}=250)\end{array}$ & $\begin{array}{c}\text { Neutral or } \\
\text { Disagree } \\
\text { or Strongly } \\
\text { Disagree } \\
(\mathrm{N}=33)\end{array}$ & $\begin{array}{c}P \\
\text { Value }\end{array}$ \\
\hline \multicolumn{7}{|l|}{ Racial Justice Curriculum } \\
\hline Yes & $78(41.1 \%)$ & $9(9.7 \%)$ & $<.001$ & $83(33.2 \%)$ & $4(12.1 \%)$ & .014 \\
\hline No & $112(59.0 \%)$ & $84(90.3 \%)$ & & $167(66.8 \%)$ & $29(87.9 \%)$ & \\
\hline $\begin{array}{l}\text { Years as a program director current } \\
\text { position, mean, } n(S D)\end{array}$ & $5.5(5.5)$ & $7.3(6.2)$ & .015 & $5.8(5.5)$ & $8.3(7.7)$ & .019 \\
\hline $\begin{array}{l}\text { Years in current program director } \\
\text { role, mean, } n \text { (SD) }\end{array}$ & $6.3(6.3)$ & $8.2(6.5)$ & .024 & $6.7(6.2)$ & $9.2(7.7)$ & .031 \\
\hline Female program director, n (\%) & $92(48.7)$ & $30(34.1)$ & .023 & $113(45.6)$ & $9(31.0)$ & .136 \\
\hline \multicolumn{7}{|l|}{ Size of Community, $\mathbf{n}$ (\%) } \\
\hline Less than 30,000 & $18(9.5)$ & $12(13.0)$ & .051 & $27(10.8)$ & $3(9.45)$ & .029 \\
\hline 30,000 to 74,000 & $29(15.3)$ & $23(25.0)$ & & $44(17.6)$ & $8(25.0)$ & \\
\hline 75,000 to 149,999 & $37(19.5)$ & $18(19.6)$ & & $51(20.4)$ & $4(12.5)$ & \\
\hline 150,000 to 499,000 & $48(25.3)$ & $20(21.7)$ & & $61(24.4)$ & $7(21.9)$ & \\
\hline 500,000 to 1 million & $22(11.6)$ & $13(14.1)$ & & $26(10.4)$ & $9(28.3)$ & \\
\hline More than 1 million & $36(19.0)$ & $6(6.5)$ & & $41(16.4)$ & $1(3.1)$ & \\
\hline
\end{tabular}

Variables not shown are program type, geographic region, total residents, percent international medical graduates, percent underrepresented minority in medicine residents, percent underrepresented in medicine faculty, race, and Latino/a ethnicity. 
Figure 1: Percent for Most Important and Second Most Important Barriers to Implementing Racial Justice Curriculum in Family Medicine Residency Training Programs $(n=283)$

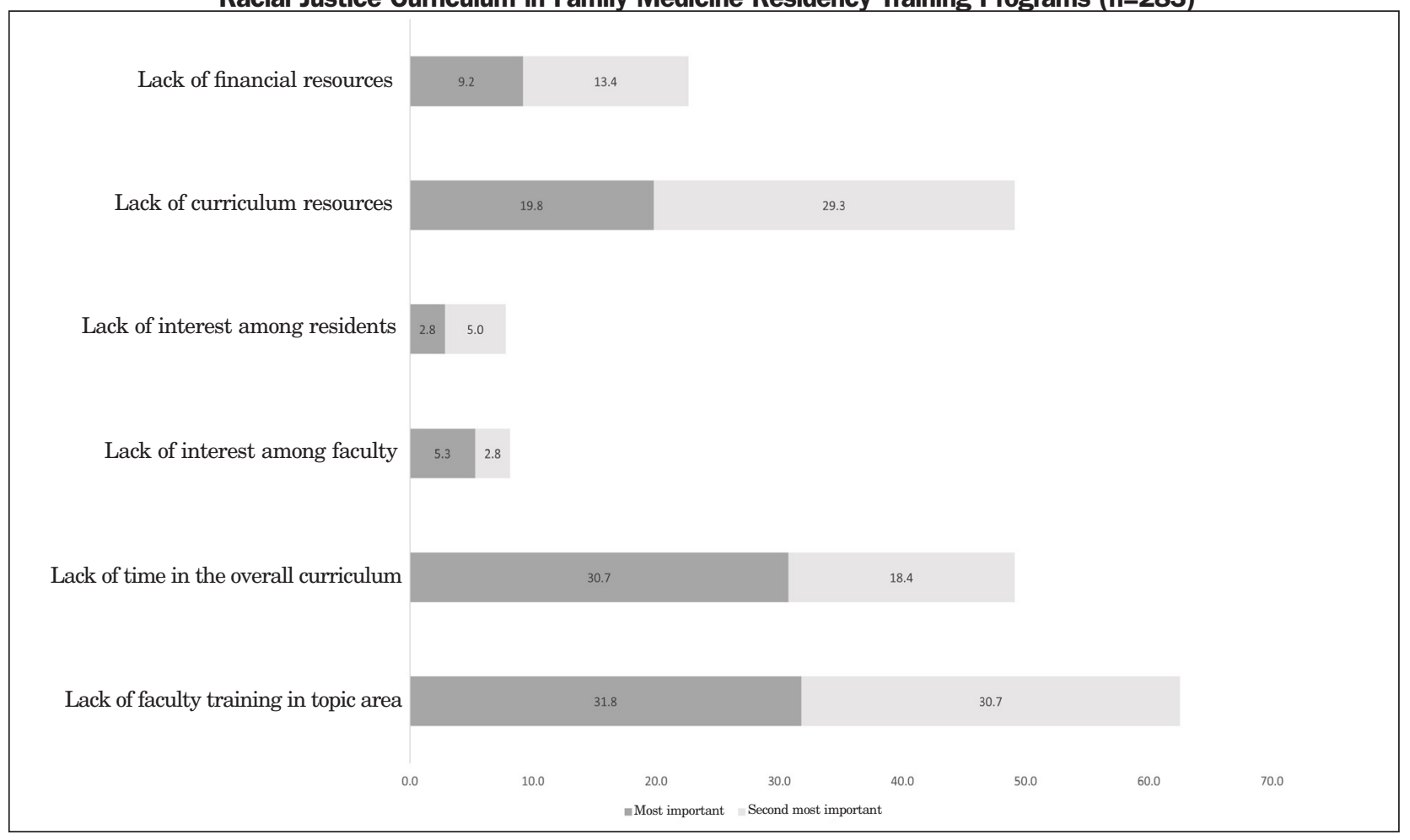

(82.5\%, Table 3). FMRPs with formal RJC were more likely to have PDs with favorable attitudes toward the inclusion of formal $\mathrm{RJC}$ in residency training and toward the importance of family physicians understanding structural racism. Female PDs were more likely than male PDs $(75.4 \%$ vs $60.9 \%, P<.02$ ) to believe that formal RJC should be included in residency training. On average, fewer years as a PD and fewer years in current directorship role were associated with favorable attitudes toward RJC in residency training (Table 3 ).

\section{Racial Justice Curriculum Components}

The majority of programs $(69.3 \%)$ do not have formal RJC (Table 4). Among the residencies with formal $\mathrm{RJC}(87,30.7 \%)$, the majority reported curriculum focused on implicit/ unconscious racial bias training (86, $98.9 \%$ ), while $54 \%$ and $50 \%$ included education on the history of racism in medicine and the history of racism in the United States, respectively (Table 4). Nearly half of FMRPs with formal RJC $(41,47.1 \%)$ reported 4-10 hours of curriculum. The majority of FMRPs with formal RJC $(68,78.1 \%)$ had 10 hours or less of curriculum total. A minority of programs with formal RJC (seven programs or $2.4 \%$ of the total program respondents) reported more than 20 hours of curriculum.

\section{Barriers to Implementation}

The most significant barriers to implementation for FMRPs with and without RJC included lack of faculty training in this area (31.8\%), lack of time $(30.7 \%)$ in the overall curriculum, and lack of curriculum resources $(20.1 \%)$. These three barriers were also cited as the next most important barrier among FMRPs with and without RJC (training $31.8 \%$, curriculum resources $29.3 \%$, and time 18.4\%). Only FMRPs without RJC reported a lack of interest among faculty as a barrier. In bivariate analysis among all barriers, a lack of faculty interest was significantly associated with programs without RJC $(7.7 \%$ vs $0 \%, P<.05)$.

\section{Discussion}

The findings of this CERA national survey of ACGME-accredited US family medicine residency program directors were consistent with our hypotheses. The majority of PDs believe that it is important for family physicians to understand structural racism and that formal racial justice curriculum should be included in FMRPs. However, fewer than onethird of FMRPs include formal RJC. The FMRPs that report having formal RJC are more likely to have residents who identify as URMM, have at least one URMM faculty member, and serve a patient population where the majority of patients identify as Black, Latino/a, and/or Native American.

The most significant barriers to implementation of RJC provided by PDs are lack of time, lack of faculty training, and lack of curriculum resources. Of the $30 \%$ of FMRPs with formal RJC, most report including 4-10 hours of curriculum and the most commonly included components are implicit/unconscious bias 
Table 4: Presence of Racial Justice Curriculum, Components of Racial Justice Curriculum, and Characteristics of Respondent Family Medicine Residency Programs With a Racial Justice Curriculum

\begin{tabular}{|c|c|c|}
\hline Racial Justice Curriculum Characteristics & $\begin{array}{l}\text { All Respondent } \\
\text { Programs } \\
\text { N=283 }\end{array}$ & $\begin{array}{c}\text { Programs With } \\
\text { Racial Justice } \\
\text { Curriculum } \\
\mathbf{N}=87\end{array}$ \\
\hline \multicolumn{3}{|l|}{ Did your residency program have a racial justice curriculum? n (\%) } \\
\hline Yes & $87(30.7)$ & -- \\
\hline No & $196(69.3)$ & -- \\
\hline \multicolumn{3}{|l|}{ Which component(s) is/are included in your program's RJC, ${ }^{*} n(\%)$} \\
\hline Implicit/unconscious racial bias training that specifically addresses structural racism & -- & $86(98.9)$ \\
\hline Education on the history of racism in medicine & -- & $47(54.0)$ \\
\hline Education on the history of racism in the United States & -- & $44(50.6)$ \\
\hline Other education that specifically addresses structural racism & -- & $55(63.2)$ \\
\hline \multicolumn{3}{|l|}{ Total hours of your formal RJC for residents, $\mathbf{n}(\%)$} \\
\hline $1-3$ & -- & $27(31.0)$ \\
\hline $4-10$ & -- & $41(47.1)$ \\
\hline $11-20$ & -- & $12(13.8)$ \\
\hline More than 20 & -- & $7(8.1)$ \\
\hline
\end{tabular}

Abbreviation: RJC, racial justice curriculum.

*Response options were all that apply.

training and education on the history of racism in medicine and the United States. Given the call from medical organizations for physicians to understand and address structural racism, graduate medical education programs would benefit from guiding organizations, such as the ACGME, creating requirements and competencies related to this content area and building on the current shared curriculum libraries. In addition, residency programs should include racism as part of social determinants of health (SDOH) education. The $\mathrm{SDOH}$ are defined by the World Health Organization as

the conditions in which people are born, grow, work, live, and age, and the wider set of forces and systems shaping the conditions of daily life, including economic policies and systems, development agendas, social norms, social policies, and political systems.

Done thoughtfully and well, this would strengthen competencybased education efforts in the system-based practice, interpersonal communication, medical knowledge, professionalism, patient care, and practice-based learning ACGME competencies.

To our knowledge, this is the first study to describe the prevalence and characteristics of RJC in family medicine residency programs or any graduate medical education specialty. The impact of racism in medical education and medicine is welldocumented, from curriculum that teaches medical learners about racial disparities without acknowledging the history and impact of structural racism to the burdens of microaggressions and the minority tax experienced by URMM residents. ${ }^{25-28}$ Our findings build on a growing body of literature aimed at addressing racism in medicine through antiracism education. ${ }^{7,28-30}$ Antiracism education is characterized as education that identifies systemic oppression, recognizes personal complicity in oppression, and develops strategies to transform structural inequities. ${ }^{31,32}$ Examples of antiracism education in medicine include the "Anti-racism in Medicine Collection" published by the American Association of Medical
Colleges, the "Anti-Racism Toolkit" published by the Association for Prevention and Teaching Research, and the "Toolkit for Teaching about Racism" published by the Society of Teachers of Family Medicine. ${ }^{33-35}$

Limitations to our evaluation include the response rate, selection bias, and recall bias. The overall response rate to the CERA survey was $50 \%$; of those survey participants, $91 \%$ completed our module. It is probable that FMRPs that have RJC were more likely to complete our module, resulting in an overestimation of the prevalence of curricula. It is also likely that PDs with an interest in racial justice were more likely to respond to our module, which would overestimate the actual percentage of PDs who believe that formal RJC should be included in FMRPs. Given the recent increase in public attention to racism and discourse about racism in medicine, the responses may reflect the decision of some respondents to provide socially desirable responses. PDs reporting the presence of RJC at their programs may have inaccurately recalled the total number of 
hours dedicated to the curriculum. As such, it is possible that the relative low presence of RJC (30\% of respondents) reflects an overestimation and overvaluation of RJC in FMRPs. Given that the survey exclusively examined FMRPs, the results may not be generalizable to graduate medical education programs in other specialties.

There is ample space for exploring this area of medical education. Further research is needed to assess existing RJCs by evaluating the content, length, and frequency of educational modules, reviewing the modes of implementation, assessing the impact on physician/learner attitudes and behaviors, and evaluating impact on patient care and outcomes. Additional research should also examine barriers to implementing RJC and determine strategies for overcoming them, particularly focused on faculty development and training. Finally, research is needed to gather data about antiracism education in other medical specialties.

\section{Conclusions}

Despite the requirement for graduate medical education to train physicians who can understand and address health disparities and the recognition that structural racism is a cause of health disparities, fewer than one-third of FMRPs include formal RJC. Given the most-reported barriers-lack of faculty training, time, and curriculum resources-residency programs would benefit from formal requirements for RJC with related competencies and shared curricular resources. Additional research should examine the content and impact of current RJC as well as the barriers to implementation and strategies to overcome them. Including robust antiracism education in residency programs is a necessary step toward training family physicians who are equipped to care for diverse communities and eliminate health disparities.

CORRESPONDING AUTHOR: Address correspondence to Dr Maria H. Wusu, Morehouse School of Medicine, Department of Family Medicine, 720 Westview Dr, Atlanta, GA 30310. mwusu@msm.edu.

\section{References}

1. ACGME Common Program Requirements (Residency). Accreditation Council for Graduate Medical Education. 2020. Accessed July 20, 2021. https://www.acgme.org/Portals/0/ PFAssets/ProgramRequirements/CPRResidency2021.pdf

2. Healthy People 2020: Disparities. Office of Disease Prevention and Health Promotion. Updated August 27, 2021. Accessed July 20, 2021. https://www.healthypeople.gov/2020/ about/foundation-health-measures/Disparities

3. Structural Racism is a Public Health Crisis: Impact on the Black Community. American Public Health Association Policy Number: LB20-04 2020. Published October 24, 2020. Accessed July 20, 2021. https://www.apha.org/ policies-and-advocacy/public-health-policystatements/policy-database/2021/01/13/structural-racism-is-a-public-health-crisis

4. 11 Terms You Should Know to Better Understand Structural Racism. Aspen Institute. Published July 2016. Accessed February 5 2021. https://www.aspeninstitute.org/blog-posts/ structural-racism-definition/

5. Bailey ZD, Krieger N, Agénor M, Graves J, Linos N, Bassett MT. Structural racism and health inequities in the USA: evidence and interventions. Lancet. 2017;389(10077):14531463. doi:10.1016/S0140-6736(17)30569-X

6. Lawrence K, Keleher T. Chronic disparity: strong and pervasive evidence of racial inequalities, race and public policy conference. Published 2004. Accessed February 5, 2021. https://www.intergroupresources.com/rc/Definitions $\% 20$ of $\% 20$ Racism.pdf

7. White-Davis T, Edgoose J, Brown Speights JS, et al. Addressing racism in medical education: an interactive training module. Fam Med. 2018;50(5):364-368. doi:10.22454/ FamMed.2018.875510

8. Perdomo J, Tolliver D, Hsu H, et al. Health equity rounds: an interdisciplinary case conference to Address implicit bias and structural racism for faculty and trainees. MedEdPORTAL. 2019;15(1):10858. doi:10.15766/ mep_2374-8265.10858

9. Tsai J, Crawford-Roberts A. A call for critical race theory in medical education. Acad Med. 2017;92(8):1072-1073. doi:10.1097/ ACM.0000000000001810
10. Hardeman RR, Medina EM, Kozhimannil KB. Structural racism and supporting black lives - the role of health professionals. N Engl J Med. 2016;375(22):2113-2115. doi:10.1056/ NEJMp1609535

11. Larson NI, Story MT, Nelson MC. Neighborhood environments: disparities in access to healthy foods in the U.S. Am J Prev Med. 2009;36(1):74-81. doi:10.1016/j. amepre.2008.09.025

12 Health Coverage by Race and Ethnicity, 2010-2019. Kaiser Family Foundation. 2021. Accessed July 20, 2021. https://www.kff.org/ racial-equity-and-health-policy/issue-brief/ health-coverage-by-race-and-ethnicity/

13. Jennings V, Gaither CJ. Approaching environmental health disparities and green spaces: an ecosystem services perspective. Int J Environ Res Public Health. 2015;12(2):1952-1968. doi:10.3390/ijerph120201952

14. Forde AT, Sims M, Muntner P, et al. Discrimination and hypertension risk among African Americans in the Jackson Heart Study. Hypertension. 2020;76(3):715-723. doi:10.1161/ HYPERTENSIONAHA.119.14492

15. Hall WJ, Chapman MV, Lee KM, et al. Implicit racial/ethnic bias among health care professionals and its influence on health care outcomes: A Systematic Review. Am J Public Health. 2015;105(12):e60-e76. doi:10.2105/ AJPH.2015.302903

16. Naumburg EH, Edgoose J. The time is now. Fam Med. 2019;51(1):11-13. doi:10.22454/ FamMed.2019.557804

17. Sexton SM, Richardson CR, Schrager SB, et al. Systemic racism and health disparities: a statement from editors of family medicine journals. Ann Fam Med. 2021;19(1):2-3. doi:10.1370/afm.2613

18. American Academy of Family Physicians. Institutional racism in the health care system. Published 2019. Accessed June 9, 2021. https:// www.aafp.org/about/policies/all/institutionalracism.html

19. Anti-Racism Commitment. Association of Departments of Family Medicine. Accessed February 9, 2021. https://adfmwebsite.azurewebsites.net/media/1874/statement-to-adfmre-anti-racism.pdf.

20. Brown SR. Association of Family Medicine Residency Directors. AFMRD Prez Release. AFMRD website. Published June 3, 2020. Accessed February 9, 202. https://www.afmrd.org/ page/stevebrownmessages

21. Grumbach K, Hart LG, Mertz E, Coffman J, Palazzo L. Who is caring for the underserved? A comparison of primary care physicians and nonphysician clinicians in California and Washington. Ann Fam Med. 2003;1(2):97-104. doi:10.1370/afm.49 
22. Xu G, Fields SK, Laine C, Veloski JJ, Barzansky B, Martini CJ. The relationship between the race/ethnicity of generalist physicians and their care for underserved populations. Am J Public Health. 1997;87(5):817-822. doi:10.2105/ AJPH.87.5.817

23. Komaromy M, Grumbach K, Drake M, et al. The role of black and Hispanic physicians in providing health care for underserved populations. N Engl J Med. 1996;334(20):1305-1310. doi:10.1056/NEJM199605163342006

24. Seehusen DA, Mainous AG III, Chessman AW. Creating a centralized infrastructure to facilitate medical education research. Ann Fam Med. 2018;16(3):257-260. doi:10.1370/afm.2228

25. Fnais $\mathrm{N}$, Soobiah $\mathrm{C}$, Chen $\mathrm{MH}$, et al. Harassment and discrimination in medical training: a systematic review and meta-analysis. Acad Med. 2014;89(5):817-827. doi:10.1097/ ACM.0000000000000200

26. Osseo-Asare A, Balasuriya L, Huot SJ, et al. Minority resident physicians' views on the Role of race/ethnicity in their training experiences in the workplace. JAMA Netw Open. 2018;1(5):e182723. doi:10.1001/jamanetworkopen.2018.2723

27. Cyrus KD. A piece of my mind: medical education and the minority tax. JAMA 2017;317(18):1833-1834. doi:10.1001/ jama.2017.0196
28. Brooks KC. A silent curriculum. JAMA. 2020;323(17):1690-1691. doi:10.1001/ jama.2020.2879

29. Medlock M, Weissman A, Wong SS, et al. Racism as a unique social determinant of mental health: development of a didactic curriculum for psychiatry residents. MedEdPORTAL. 2017;13(1):13. doi:10.15766/mep_23748265.10618

30. DallaPiazza M. Padilla-Register M, Dwarakanath M, Obamedo E, Hill J, Soto-Greene ML. Exploring racism and health: an intensive interactive session for medical students. MedEdPORTAL. 2018;14:10783.

31. Lynch I, Swartz S, Isaacs D. Anti-racist moral education: a review of approaches, impact and theoretical underpinnings from 2000 to 2015. J Moral Educ. 2017;46(2):129-144. doi:10.1080 /03057240.2016.1273825

32. Adopting an anti-racist medical curriculum. The bmjopinion. Published February 19, 2021. Accessed July 20, 2021. https://blogs.bmj.com/ bmj/2021/02/19/adopting-an-anti-racist-medical-curriculum/\#origin=https $\% 3 \mathrm{~A} \% 2 \mathrm{~F} \% 2 \mathrm{Fdis}$ qus.com\&rpcToken=886410882 $1049675 \&$ cle $\operatorname{arCache}=1$

33. Anti-Racism Toolkit: Curricula. Association for Prevention Teaching and Research. Accessed July 20, 2021. https://www.aptrweb.org/page/ curricula
34. Anti-racism in Medicine Collection. AAMC. MedEdPortal. Accessed July 20, 2021. https:// www.mededportal.org/anti-racism

35. Anderson A, Speights JSB, Bullock K, et al. Toolkit for teaching about racism in the context of persistent health and healthcare disparities. STFM Resource Library. May 2017. Accessed July 20, 2021. https://resourcelibrary.stfm.org/ HigherLogic/System/DownloadDocumentFile. ashx?DocumentFileKey=cf40991e-96e9-3e15ef15-7be20cb04dc1\&forceDialog=0 